\title{
Geographic Information Systems (GIS) Demonstrating Primary Care Needs for a Transitioning Hispanic Community
}

\author{
Michael F. Dulin, MD, PhD, Thomas M. Ludden, MA, Hazel Tapp, PhD, \\ Heather A. Smith, PhD, Brisa Urquieta de Hernandez, BUS, Joshua Blackwell, MS, \\ and Owen J. Furuseth, PhD
}

Background: Hispanics are the largest and fastest growing minority group in the United States. Charlotte, NC, had the 4th fastest growing Hispanic community in the nation between 1990 to 2000. Gaining understanding of the patterns of health care use for this changing population is a key step toward designing improved primary care access and community health.

Methods: The Multiple Attribute Primary Care Targeting Strategy process was applied to key patientand community-level attributes describing the Charlotte Hispanic community. Maps were created based on socioeconomic status, population density, insurance status, and use of the emergency department as a primary care safety net. Each of these variables was weighed and added to create a single composite map.

Results: Individual attribute maps and the composite map identified geographic locations where Hispanic community members would most benefit from increased access to primary care services.

Conclusions: Using the Multiple Attribute Primary Care Targeting Strategy process we were able to identify geographic areas within our community where many Hispanic immigrants face barriers to accessing appropriate primary care services. These areas can subsequently be targeted for interventions that improve access to primary care and reduce emergency department use. The geospatial model created through this process can be monitored over time to determine the effectiveness of these interventions. (J Am Board Fam Med 2010;23:109-120.)

The US health care system is searching for ways to increase health care coverage and reduce costs. One clear strategy is to increase the access to and use of primary care and preventative services. ${ }^{1,2}$ Policy changes that increase access to these services must weigh both the community's primary care needs and the provider workforce. ${ }^{2-5}$ Hispanics are the largest and fastest growing minority group in the

This article was externally peer reviewed.

Submitted 1 June 2009; revised 31 August 2009; accepted 8 September 2009.

From the Department of Family Medicine, Carolinas Healthcare System (MFD, HT, BUdH) and the Department of Geography and Earth Sciences, University of North Carolina (TML, HAS, JB, OJF), Charlotte, NC.

Funding: This work was supported by grants from the Charlotte-Mecklenburg Health Services Foundation and the Agency for Healthcare Research and Quality (AHRQ), R03 HS016023-01.

Conflict of interest: none declared.

Corresponding autbor: Hazel Tapp, $\mathrm{PhD}$, Elizabeth Family Medicine, 2001 Vail Avenue, 4th Floor, Suite 400, Charlotte, NC 28207 (E-mail: hazel.tapp@carolinashealthcare.org).
United States. ${ }^{6}$ In addition, Hispanic community members are less likely to have a regular source of care and subsequently have lower rates of receiving many preventive services. ${ }^{7}$

Many barriers prevent access to primary care services for the Hispanic populations in our community, including (1) lack of medical insurance, (2) socioeconomic factors, (3) language barriers, (4) lack of transportation to services, and (5) mistrust of the medical system. ${ }^{8}$ This causes many community members to forgo needed preventive medical services and wait until significant progression of their disease has occurred before they seek medical care. When medical services are obtained, they are often provided by alternative providers or acute care services. This inappropriate use of the emergency department (ED) for primary care services results in higher medical costs, overtaxing of the $\mathrm{ED}$, and a negative impact on quality of care for all. ${ }^{9,10}$ 
In contrast, primary care access builds doctorpatient relationships, improves treatment adherence and follow-up, decreases inappropriate use of EDs, and reduces hospitalization rates. ${ }^{10}$ Subsequently, overcoming barriers to primary care services for our community's underserved Hispanic population has the potential to reduce medical costs, improve quality of care, and enhance overall community health. ${ }^{11}$

For several reasons, our community provides an ideal setting in which to develop and monitor interventions that can improve access to primary care. First, Charlotte, NC, was the fourth-ranked metropolitan area in the nation in terms of proportional Hispanic growth, with a $932 \%$ increase between 1990 and 2000. ${ }^{12}$ This rapidly changing population must overcome many health care barriers, including a lack of overall capacity to receive primary care and preventive services. Second, preliminary data from our community shows that between $60 \%$ and $70 \%$ of all ED visits by Hispanic community members are for primary care preventable or treatable illness. Third, we have developed a regional primary care research network that has brought together health providers, community members, and researchers with the shared goal of improving community health by increasing access to primary care services. This network, The Mecklenburg Area Partnership for Primary Care Research (MAPPR) has embraced the ideals of community-based participatory research to build the partnerships needed to address health disparities for vulnerable populations, including Hispanic immigrants. Community-based participatory research is a mechanism for improving community health, effecting social change, and ameliorating health disparities within disadvantaged communities and that focuses on equal partnerships between researchers, clinicians, and community members during the research process. The network implemented principles of community-based participatory research by including community members in all steps of the research process-from development of the research question and oversight of data collection to data analysis and interpretation. Fourth, this network includes the third largest vertically integrated hospital system in the country: Carolinas Health Care System (CHS). This hospital system provides the majority of medical care for our community's uninsured patients, allowing our research team to explore patterns of health care utilization for this underserved population. Based on previous unpublished work, focus groups of patients and providers in our community have suggested several possible reasons for why a patient may not use an available safety clinic despite its close proximity. The barriers identified included lack of education about the medical resources available, fear of persecution secondary to a lack of documentation or discrimination, inconvenient clinic hours coupled with an inability to miss work, language barriers, and long waiting times before the next available appointment.

As first steps to improving access to primary care services for the immigrant population, our team needed to identify geographic areas to target and have a robust system in place to evaluate the success of an intervention. To achieve these goals, we used the Multiple Attribute Primary Care Targeting Strategy (MAPCATS) system to analyze $5 \mathrm{key}$ attributes describing the community's Hispanic population. ${ }^{13}$ To start this process the MAPPR Community Advisory Board (CAB) developed the research question: Where in our community would Hispanic immigrants most benefit from increased access to primary care services?

\section{Methods}

This project was designed and overseen by the MAPPR network, a partnership between primary care providers, community members, and research team members. The network's CAB consisted of the following members: The Carolinas Medical Center (CMC) Ambulatory Clinic System (CMC Eastland Family Practice Clinic, CMC NorthPark Clinic, and CMC Biddle Point Clinic); Our Lady of Guadalupe Church; The Bethesda Clinic (a local free clinic); The Mecklenburg County Health Department; The Department of Family Medicine; University of North Carolina at Charlotte Geography and Earth Sciences Department; and the Latin American Coalition. The CAB for the research network provided input and oversight for the research process using principles of community-based participatory research. ${ }^{14}$ During this project the advisory board involvement spanned from development of the research question to selection of attributes to oversight of research process and review of results.

The previously described MAPCATS process was applied to address the need for increased pri- 
mary care access for the Charlotte Hispanic community (see companion paper earlier in this volume). ${ }^{13}$ The MAPPR team then identified 5 measurable attributes describing primary care needs for the Hispanic community. These attributes included (1) socioeconomic status, (2) population density, (3) insurance status, (4) inappropriate utilization of the ED, and (5) use of a primary care safety-net clinic.

After institutional review board approval was obtained, the raw data were extracted from the shared CHS databases; this data included insurance status, race/ethnicity, and information about ED and primary care clinic use. Additional censusbased demographic data describing the racial and ethnic makeup for Mecklenburg County was purchased from Claritas (San Diego, CA). Capturing and incorporating data from 2 different sources and at 2 nested scales allowed the research team to reflect a more comprehensive and health-relevant portrait of the population, confirm accuracy of the different data points and assess the degree to which particular areas of our community-and the populations resident within those areas-were underserved with regard to primary health care options. The New York University ED algorithm was used to evaluate ED visits and determine whether they were primary care treatable or preventable. ${ }^{15}$

The raw data from the CHS database was processed to be included in the geographic information systems (GIS) analysis in the following sequence. First, the data were narrowed down to only those patients in Mecklenburg County. Second, the original address and any other data used to identify patients (apart from an assigned geocode) was stripped from the data set to protect patient identification. Third, all patient data were reviewed to identify any census tracts with fewer than 50 community members of any single racial or ethnic group. If present, these data were removed and/or averaged into an adjacent census tract to preclude the possible identification of patients in the resultant maps.

All additional community descriptive data, including Hispanic population density, household income, and county race/ethnic data, were imported into ArcGIS (ESRI, Redlands, CA), allowing the team to assign weights to each attribute before creating maps. The next step in the MAPCATS process was to map out each attribute individually. Members of the research team and CAB reviewed maps of individual attributes to confirm that the data fit their perceptions of the primary care needs of the Hispanic community. Committee feedback included (1) what data were needed for the analysis, (2) how to weigh each measure, (3) the study area for the project, and (4) data exclusion criteria. The committee also confirmed measures for the protection of the data and to prevent patient identification. Next, combined maps were assembled based on several iterative evaluations of individual maps to determine appropriate weightings for a final map. Finally, combination maps incorporating assessed weightings were assembled, showing areas of Charlotte in need of increased primary care access specifically for the Hispanic community.

\section{Map Creation}

All potential attributes describing primary care need were mapped by census tract using ArcGIS (ESRI). Maps describing each attribute were examined by the research team and CAB; 5 key attributes linked to potential primary care demand were selected. Different data elements were examined to confirm the validity of each attribute. For example, the map of community-wide Hispanic settlement was compared with overall Hispanic ED use and was found to be proportional; maps of inappropriate ED use were compared with maps showing appropriate ED use, and these were found to be complementary. After the maps were revised based on feedback, composite maps were created using different weights for each attribute. After discussion and review of the maps, a strategy of equal weighting was selected (with the exception of primary care safety net use, which was weighted as a protective factor). The values for each of the 5 attributes were standardized, multiplied by the weighting factor, and added together for each census tract. The total was then standardized and the census tracts with values greater than $1 \mathrm{SD}$ above the mean were selected for the composite map as target areas for a primary care intervention for the Hispanic community.

\section{Results}

\section{Maps of Individual Attributes}

Five attributes were selected using the MAPCATS process. These attributes were narrowed to capture data representing only Hispanic community members (Figure 1). Socioeconomic status and popula- 
Figure 1. Final Hispanic community attributes selected via the Multiple Attribute Primary Care Targeting Strategy (MAPCATS) process.

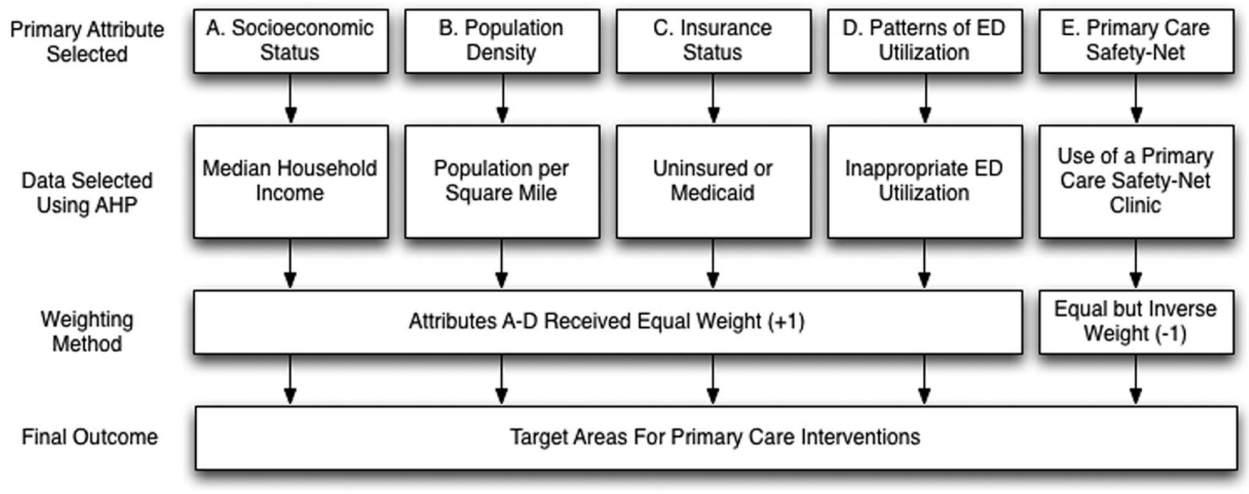

tion density data were pulled from the commercial database, Claritas. Insurance status, patterns of ED use, and primary care safety-net data came from the hospital system database.

Figure 2 shows Hispanic distribution of median household income by census tract. Lower income areas are predominate in and around the city center and to the west and east of the city. Areas with lower values of median household income indicate higher levels of need among Hispanic households for lower cost primary care services.

Figure 3 shows the Hispanic population density map using the number of people living in a census tract divided by the number of square miles in that tract. Areas with higher Hispanic population densities indicate potential areas of need and locations where centralized interventions might have the most efficient impact.

Figure 4 shows the percentage of Hispanic patients by census tract who were uninsured or have Medicaid insurance. The number of patients with either of these insurance types was divided by the total number of Hispanic community members living in each tract. Areas with higher levels of Hispanic patients who self-pay or use Medicaid were found roughly encircling and to the east of the city center, indicating higher levels of need for low-cost primary care services in these areas.

The map showing percent of inappropriate ED visits by Hispanic community members (Figure 5) reveals the percent of Hispanic ED visits for each census tract that were for primary care preventable or treatable issues. Areas with higher levels of ED use indicate higher levels of need for primary care services. Above-average use among the Hispanic com- munity comes from several residential Hispanic settlement areas and covers a broad area of locations in and around the Charlotte community. Insufficient data for the city center indicates very low Hispanic population density in this area (as noted above, a cutoff of point was selected so that any tract having 50 or fewer people was removed from the analysis).

Data for primary care safety-net clinics were used to create maps showing the percentage of the population accessing these clinics (Figure 6). It is estimated that these 4 clinics provide primary care services for almost $80 \%$ of the uninsured residents of Mecklenburg County. Areas with higher levels of use for safety-net clinics indicate both an area of need and an area in which the Hispanic population is being served. For the purposes of this article, areas with higher percentages of the population using these safety-net clinics provided a protective effect for future primary care needs. This attribute was therefore weighed equally but inversely to the other attributes in the composite model.

\section{Compilation Map}

Figure 7 shows the maps based on the combined attributes that indicated target areas for interventions to increase primary care access for the Hispanic community. These areas showed higher levels of need based on all 5 of the selected attributes. One of the most significant target areas for the Hispanic community was located to the south of the city center; this area was not adjacent to a safety-net clinic. Other target areas surrounding and to the east of the city center were located near a safety-net clinic that serves primarily African American and white patients. 
Figure 2. Hispanic distribution of median household income by census tract-Charlotte, Mecklenburg County, NC.

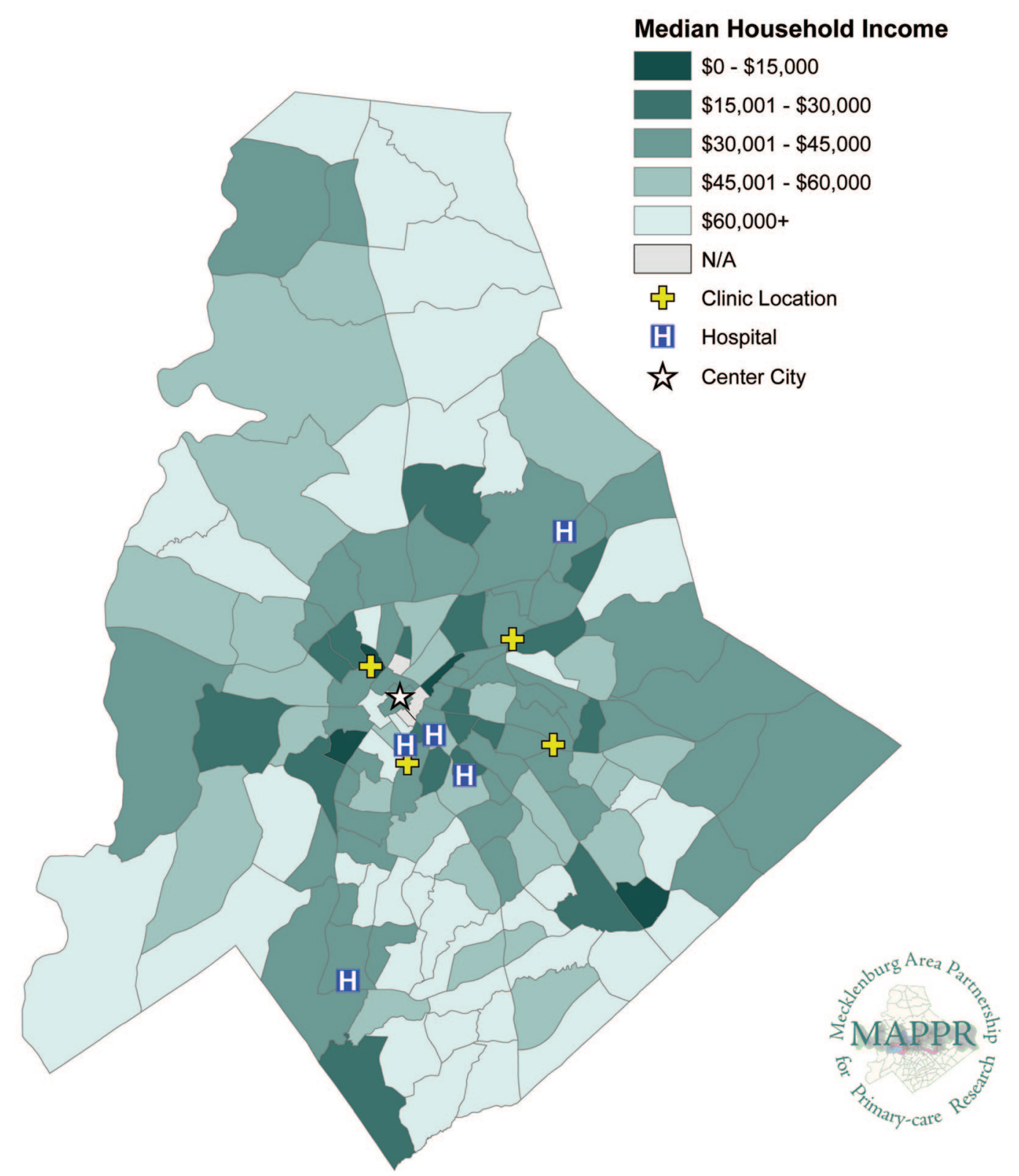

Source: Claritas Update Demographics 2007, Claritas (San Diego,CA).

\section{Discussion}

This article demonstrates a new technique (MAPCATS) that can be used to analyze patterns of health care use and other descriptive communitylevel data within a rapidly growing Hispanic com- munity. This system identified geographic areas where increased access to primary care services could have the greatest impact on improving community health. We also propose that the MAPCATS model can be used longitudinally to monitor 
Figure 3. Hispanic population density by census tract—Charlotte, Mecklenburg County, NC.

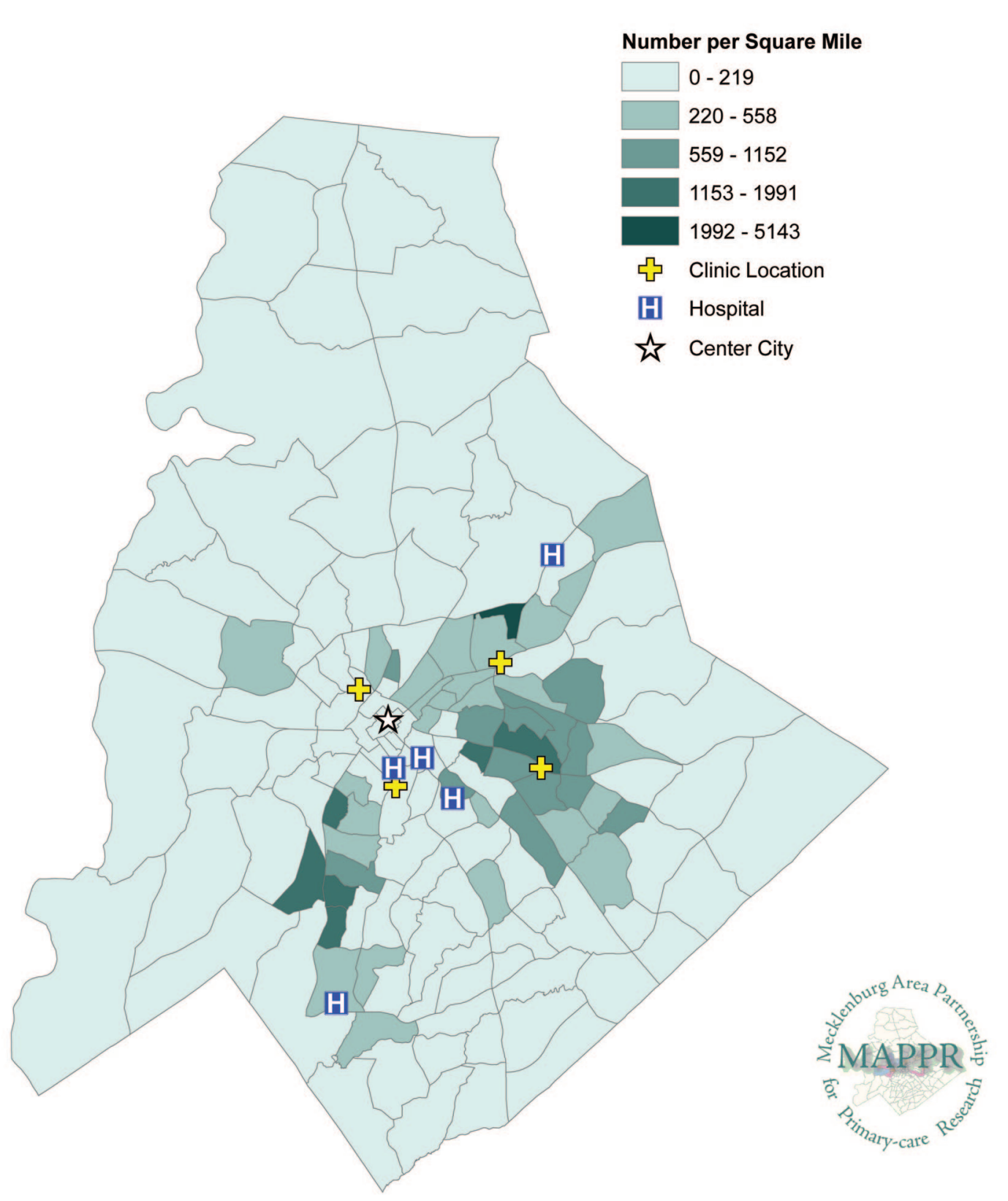

Source: Claritas Update Demographics 2007, Claritas (San Diego, CA).

changes in primary care access and need over time as a way to measure the effectiveness future interventions.

We have produced individual attribute maps that offer insight into community members' health care choices and how these relate to other community variables such as income, insurance status, and immigration settlement patterns. For example, low-income uninsured or Medicaid patients who are not in an area that can access a safety-net clinic 
Figure 4. Hispanic emergency department patients, uninsured or using Medicaid, by census tract—Charlotte, Mecklenburg County, NC.

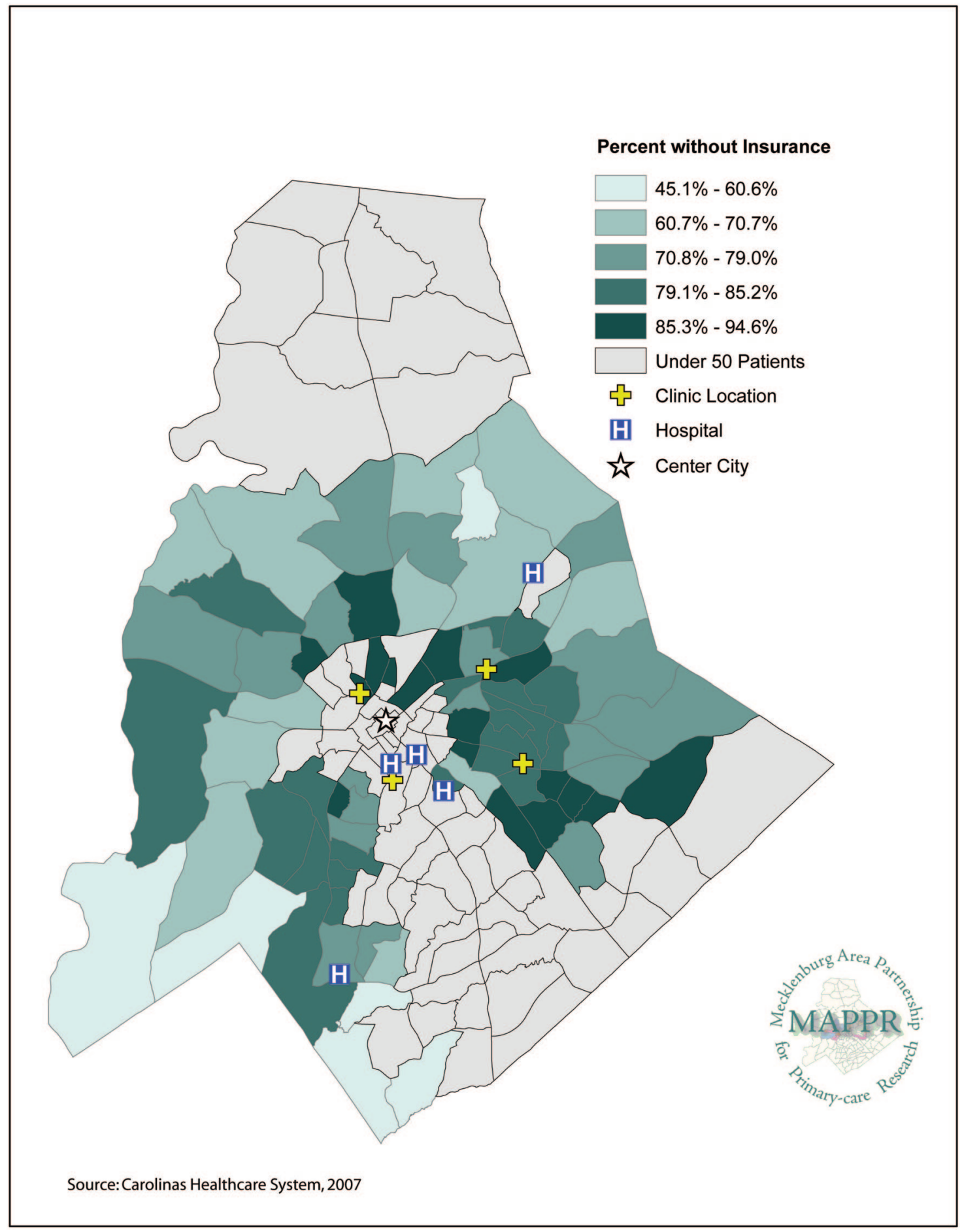

are more likely to go to the ED for problems that would be better treated or prevented at a primary care safety-net clinic. When all the attributes selected were combined to create a map of intervention target areas, we were able to provide detailed geographic information indicating where services were required and where their location would probably have the greatest positive impact; this fulfilled one of our primary goals in using the MAPCATS process and also assisted with the sec- 
Figure 5. Hispanic patient emergency department Use for primary care preventable or treatable illnesses by census tract-Charlotte, Mecklenburg County, NC.

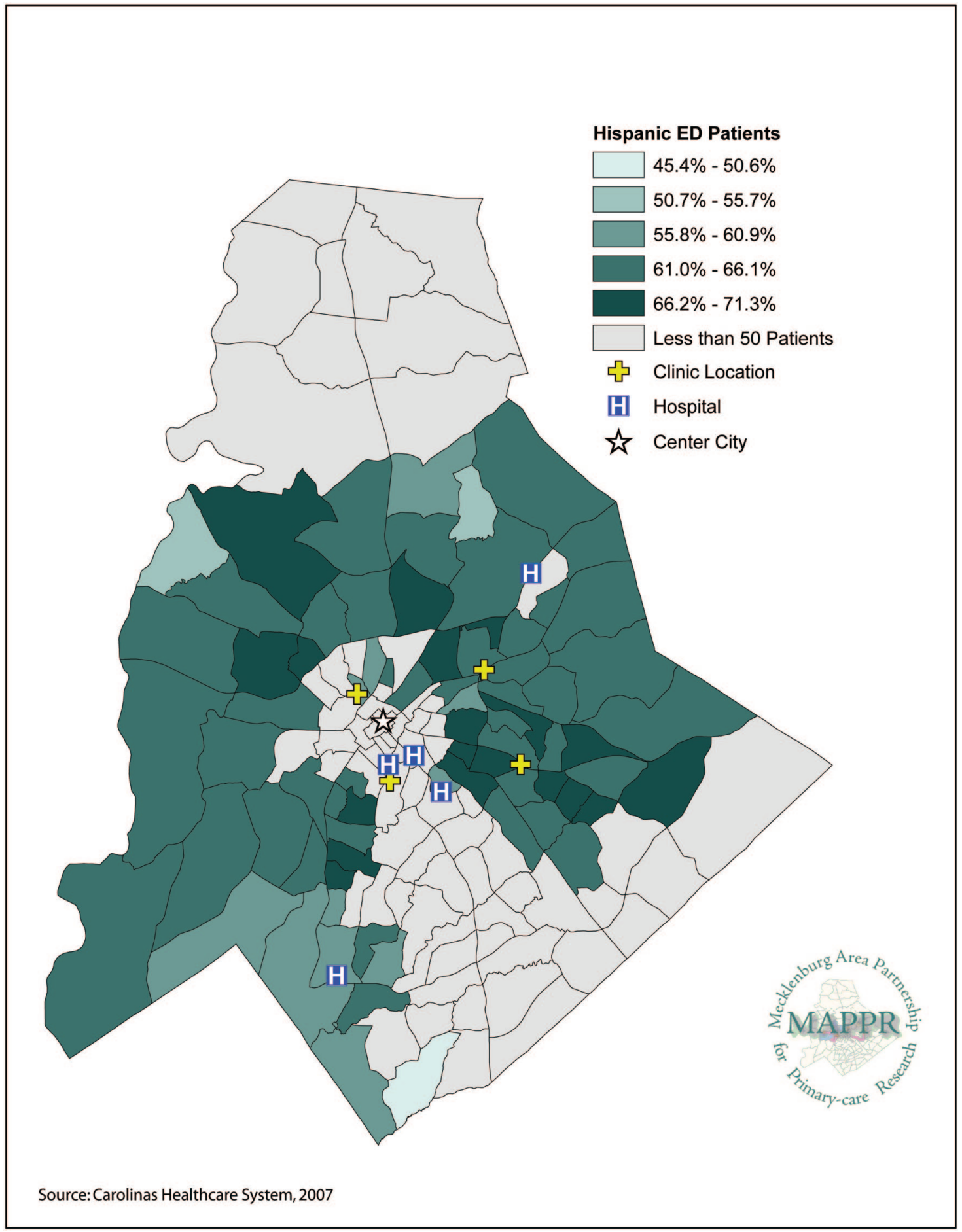

ond primary goal of decreasing primary-care related visits to the ED.

Even among American-born adults reporting a usual source of primary care, barriers to timely access such as "no transportation" or "couldn't get through on the phone" lead patients to use the ED as an alternative to primary care. ${ }^{16}$ A study of ED use in New Jersey reported that $47 \%$ of outpatient ED visits were potentially avoidable. ${ }^{17}$ Similarly, a 2001 study in Utah found that 4 out of every 10 ED 
Figure 6. Hispanic patient use of safety-net clinics by census tract—Charlotte, Mecklenburg County, NC.

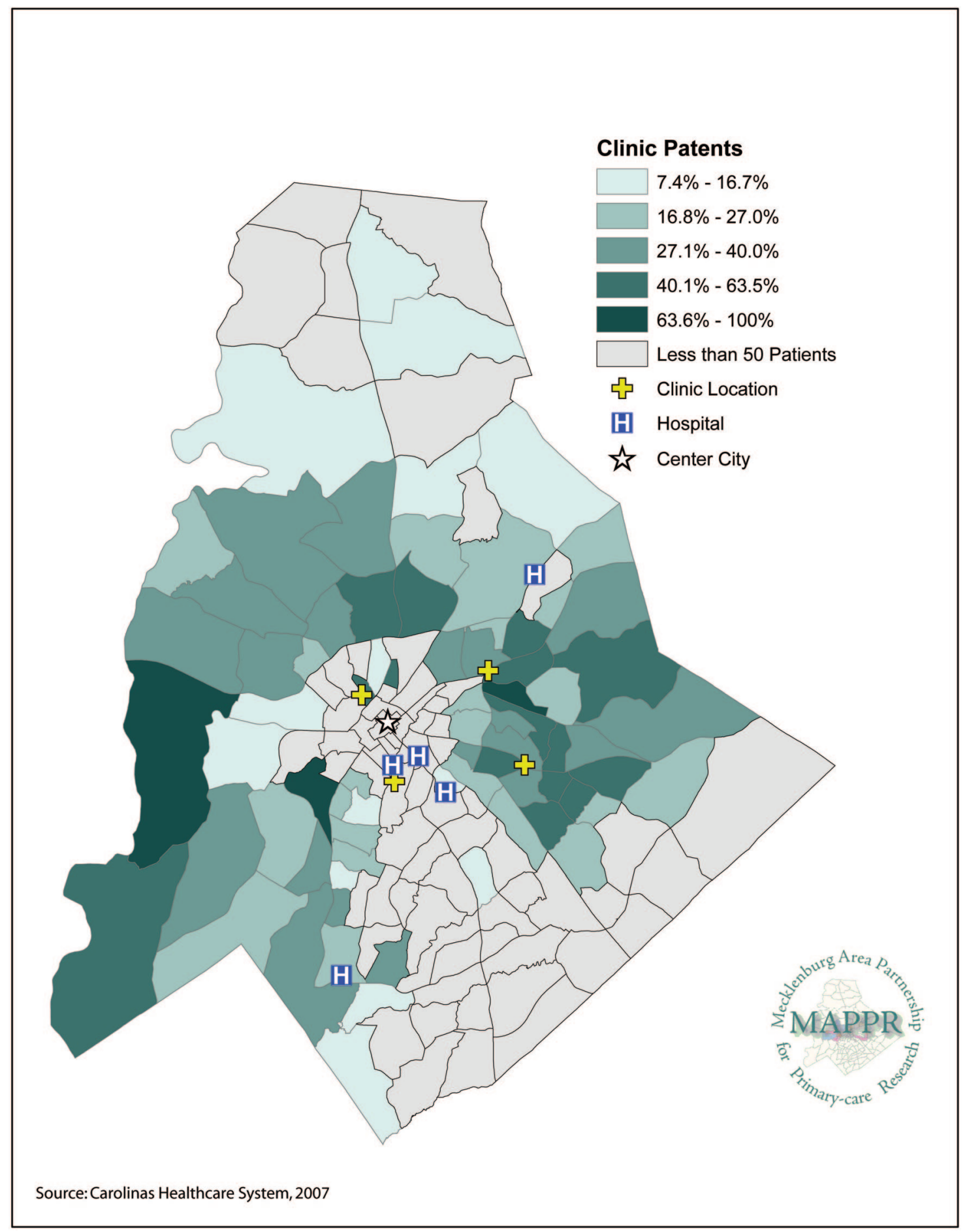

visits were identified as the primary care type. ${ }^{18}$ In Utah, primary care-type ED visits accounted for \$131 million of the state's \$281 million total ED hospital charges. ${ }^{18}$ Diverting primary care-type visits from the ED typically shows savings and improves quality of care. ${ }^{18-20}$ Calculations of savings depend on the analysis methodology used, the perspective of payer versus provider, and the different allocations of costs within a hospital's departments. ${ }^{19-23}$ Despite these potential difficulties, 
Figure 7. Target areas for interventions based on the combined attributes to increase primary care access for Hispanic population by census tract-Charlotte, Mecklenburg County, NC.



Source: Carolinas Healthcare System 2007 and Claritas Update Demographics 2007, Claritas (San Diego, CA).

considerable interest exists on the part of payers and providers to investigate possible solutions to curbing increasing costs and problems associated with ED overcrowding.
Reducing the demand for ED services depends on increasing the use of other health services and particularly on improving access to primary care for preventive and nonurgent care, and referral to spe- 
cialists. ${ }^{11}$ Primary care facilitates the building of doctor-patient relationships and access to treatment adherence, follow-up, and health education while decreasing inappropriate use of EDs, hospitalization rates, and tests requested; this would all subsequently lower associated costs. ${ }^{10}$

The Hispanic community is particularly underserved by primary care providers and suffers from disparities in both health care access and outcomes. The US Hispanic population experiences many barriers to access, as demonstrated by lower rates of health insurance coverage, a lack of ongoing medical care, decreased vaccination rates, and delayed access to prenatal care. ${ }^{24}$ Health care reform aimed at increasing access to primary care services must take into account current patterns of health services use and how this relates to descriptive community data. The MAPCATS process offers one method of using both descriptive community data and information about health care use to identify target areas within a community that would have the greatest potential benefit from increasing access to primary care and preventive services. The use of MAPCATS sets the foundation for future research in communities that are experiencing population changes. We are currently developing projects based on the MAPCATS process that will specifically address the needs for the communities that are in greater need of primary care. It will also be important to assess the communities in need compared with those with "average" accesses to understand the dynamic of primary care.

The authors would like to acknowledge Julie Courtney, Jonathan Levin, Jess George, Angeles Ortega-Moore, Heather Manos, Raquel Lynch, Kristin Wade, Rhett Brown, Irene Zinc, the providers, and the Hispanic community members who participated.

\section{References}

1. Phillips R, Miyoshi T, Fryer G. Primary care and GIS: moving knowledge to action. Abstr Acad Health Serv Res Health Policy Meet 2002;(19):33.

2. Starfield B, Shi L, Macinko J. Contribution of primary care to health systems and health. Milbank Q 2005;83:457-502.

3. Lakhan SE, Laird C. Addressing the primary care physician shortage in an evolving medical workforce. Int Arch Med 2009;2:14.

4. Brotherton SE, Rockey PH, Etzel SI. US graduate medical education, 2004-2005: trends in primary care specialties. JAMA 2005;294:1075-82.

5. Macinko J, Starfield B, Shi L. The contribution of primary care systems to health outcomes within Organization for Economic Cooperation and Development (OECD) countries, 1970-1998. Health Serv Res 2003;38:831-65.

6. US Census Bureau. Census Factfinder. Available at: http://www.factfinder.census.gov. Accessed 10 October 2008.

7. Centers for Disease Control and Prevention (CDC). Access to health-care and preventive services among Hispanics and non-Hispanics-United States, 20012002. MMWR Morb Mortal Wkly Rep 2004;53: 937-41.

8. Vines AI, Godley PA. The challenges of eliminating racial and ethnic healthcare disparities: inescapable realities? Perplexing science? Ineffective policy? N C Med J 2004;65:341-9.

9. Carret ML, Fassa AG, Kawachi I. Demand for emergency health service: factors associated with inappropriate use. BMC Health Serv Res 2007;7:131.

10. Gill JM, Mainous AG 3rd, Nsereko M. The effect of continuity of care on emergency department use. Arch Fam Med 2000;9:333-8.

11. Walls CA, Rhodes KV, Kennedy JJ. The emergency department as usual source of medical care: estimates from the 1998 National Health Interview Survey. Acad Emerg Med 2002;9:1140-5.

12. Singer A, Suro R. Latino growth in metropolitan America: changing patterns, new locations. Washington, DC: The Brookings Institution. Available at: http://www.brookings.edu/reports/2002/07 demographics_suro.aspx. Accessed 15 March 2009.

13. Dulin MF, Ludden TM, Tapp H, et al. Using geographical information systems (GIS) to understand a community's primary care needs. J Am Board Fam Med 2010;23:13-21.

14. Israel B, Eng E, Schulz A, Parker E. Methods in community-based participatory research. San Francisco: Jossey-Bass; 2005.

15. The Center for Health and Public Service Research. NYU ED Algorithm. Available at: http://wagner. nyu.edu/chpsr/index.html? $\mathrm{p}=25$. Accessed 27 July 2007.

16. Rust G, Ye J, Baltrus P, Daniels E, Adesunloye B, Fryer G. Practical barriers to timely primary care access: impact on adult use of emergency department services. Arch Intern Med 2008;168:1705-10.

17. DeLia D, Rutgets Center for State Health Policy. Potentially avoidable use of hospital emergency departments in New Jersey. Available at: http://www. cshp.rutgers.edu/Downloads/6330.pdf. Accessed 10 January 2008.

18. Utah Department of Health, Health Data Committee, Center for Health Data, Office of Health Care Statistics. Primary Care Sensitive Emergency Department Visits in Utah 2001. (April 2004) Available at: http://health.utah.gov/hda/Reports/Primary_Care_ ERvisits_Utah2001.pdf. Accessed 10 January 2008. 
19. Williams RM. The costs of visits to emergency departments. N Engl J Med 1996;334:642-6.

20. Bamezai A, Melnick G, Nawathe A. The cost of an emergency department visit and its relationship to emergency department volume. Ann Emerg Med 2005;45:483-90.

21. Williams RM. The costs of visits to emergency departments-revisited. Ann Emerg Med 2005;46: 471-2; author reply, 472-3.

22. Florence CS. Nonurgent care in the emergency de- partment: can we save by shifting the site of care? Ann Emerg Med 2005;45:495-6.

23. Showstack J. The costs of providing nonurgent care in emergency departments. Ann Emerg Med 2005; 45:493-4.

24. US Department of Health \& Human Service, Agency for Healthcare Research and Quality. National Healthcare Disparities Report, 2006. Available at: http://www.ahrq.gov/qual/nhdr06/nhdr06.htm. Accessed 10 October 2008. 